\title{
Hexane-1,2,5,6-tetrol as a Versatile and Biobased Building Block for the Synthesis of Sustainable (Chiral) Crystalline Mesoporous Polyboronates
}

\author{
Mario De bruyn, ${ }^{*}, \dagger,{ }^{\circ}$ Paolo Cuello-Penaloza, ${ }^{\dagger}$ Melissa Cendejas, ${ }^{\ddagger}$ Ive Hermans, $^{\ddagger}{ }^{\ddagger}$ Jiayue He, ${ }^{\dagger}$
} Siddarth H. Krishna, ${ }^{\dagger}$ David M. Lynn, ${ }^{\dagger}$ James A. Dumesic, ${ }^{\dagger}{ }^{\circ}$ George W. Huber, ${ }^{\dagger}$ and Bert M. Weckhuysen ${ }^{\S}$

\begin{abstract}
${ }^{\dagger}$ Department of Chemical and Biological Engineering, University of Wisconsin-Madison, 1415 Engineering Drive, Madison, Wisconsin 53706, United States

${ }^{\ddagger}$ Department of Chemistry, University of Wisconsin-Madison, 1101 University Avenue, Madison, Wisconsin 53706, United States ${ }^{\S}$ Faculty of Science, Debye Institute for Nanomaterials Science, Utrecht University, Universiteitsweg 99, 3584 CG Utrecht, The Netherlands
\end{abstract}

\section{Supporting Information}

ABSTRACT: We report on the synthesis and characterization of novel mesoporous chiral polyboronates obtained by condensation of $(R, S) /(S, S)$-hexane-1,2,5,6-tetrol (HT) with simple aromatic diboronic acids (e.g., 1,3-benzenediboronic acid) (BDB). $\mathrm{HT}$ is a cellulose-derived building block comprising two 1,2-diol structures linked by a flexible ethane bridge. It typically consists of two diastereomers one of which $[(S, R)$ $\mathrm{HT}$ ] can be made chirally pure. Boronic acids are abundantly available due to their importance in Suzuki-Miyaura coupling reactions. They are generally considered nontoxic and easy to synthesize. Reactive dissolution of generally sparingly soluble HT with $\mathrm{BDB}$, in only a small amount of solvent, yields the mesoporous HT/polyboronate materials by spontaneous precipitation from the reaction mixture. The $3 \mathrm{D}$ nature of $\mathrm{HT} /$ polyboronate materials results from the entanglement of individual $1 \mathrm{D}$ polymeric chains. The obtained BET surface areas (SAs) and pore volumes (PVs) depend strongly on HT's diastereomeric excess and the meta/para orientation of the boronic acids on the phenyl ring. This suggests a strong influence of the curvature(s) of the 1D

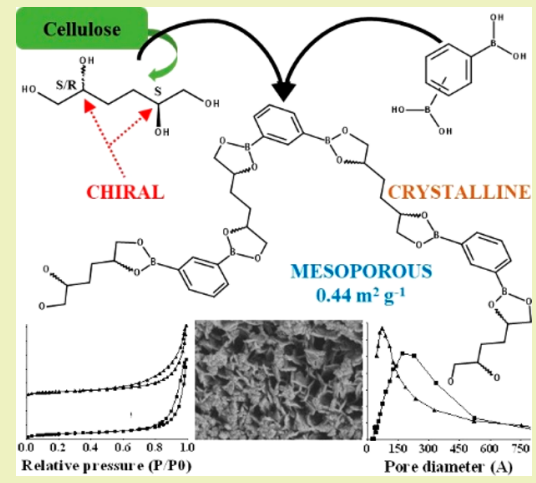
polymeric chains on the final materials' properties. Maximum SA and PV values are respectively $90 \mathrm{~m}^{2} \mathrm{~g}^{-1}$ and $0.44 \mathrm{~mL} \mathrm{~g}^{-1}$. Variably sized mesopores, spanning mainly the $5-50 \mathrm{~nm}$ range, are evidenced. The obtained pore volumes rival the ones of some covalent organic frameworks (COFs), yet they are obtained in a less expensive and more benign fashion. Moreover, currently no COFs have been reported with pore diameters in excess of $5 \mathrm{~nm}$. In addition, chiral boron-based COFs have presently not been reported. Scanning electron microscopy reveals the presence of micrometer-sized particles, consisting of aggregates of plates, forming channels and cell-like structures. X-ray diffraction shows the crystalline nature of the material, which depends on the nature of the aromatic diboronic acids and, in the specific case of 1,4-benzenediboronic acid, also on the applied diastereomeric excess in HT.

KEYWORDS: Boronates, Mesoporous, Chiral, Polymers, Cellulose

\section{INTRODUCTION}

Mesoporous materials have attracted significant attention as their wide pores $(2-50 \mathrm{~nm})$ allow for improved diffusion and accessibility, favoring applications as diverse as, controlled drug release, chromatography, adsorbents, electrodes, solar cells, and heterogeneous catalysis. ${ }^{1,2}$ Exemplary are (non) siliceous mesoporous oxides, periodic mesoporous organic silicas (PMOs), mesoporous carbons, hyperconjugated porous polymers, and some metal-organic frameworks. ${ }^{3-7}$ Often the introduction of mesopores in a material is linked to the use of (supra)molecular templates such as surfactants, but also other techniques are known like dealumination/desiliciation, nanoassemblies, and local associations of helices, among others. ${ }^{1,8}$
Boronate ester polymers (BEP) and their tendency to form hierarchical supramolecular structures have been widely reported in the literature. ${ }^{9}$ However, few micro/mesoporous materials have been reported based on $1 \mathrm{D}$ polymeric boronate esters containing backbones not involving heteroatoms (e.g., nitrogen, sulfur). Exemplary are the flowerlike micro/ mesoporous microparticles made by the condensation of 1,4benzenediboronic acid (1,4-BDB) with pentaerythritol (PE). These materials have a specific surface area of $184 \mathrm{~m}^{2} \mathrm{~g}^{-1}$

Received: May 20, 2019

Revised: June 24, 2019

Published: July 3, 2019 

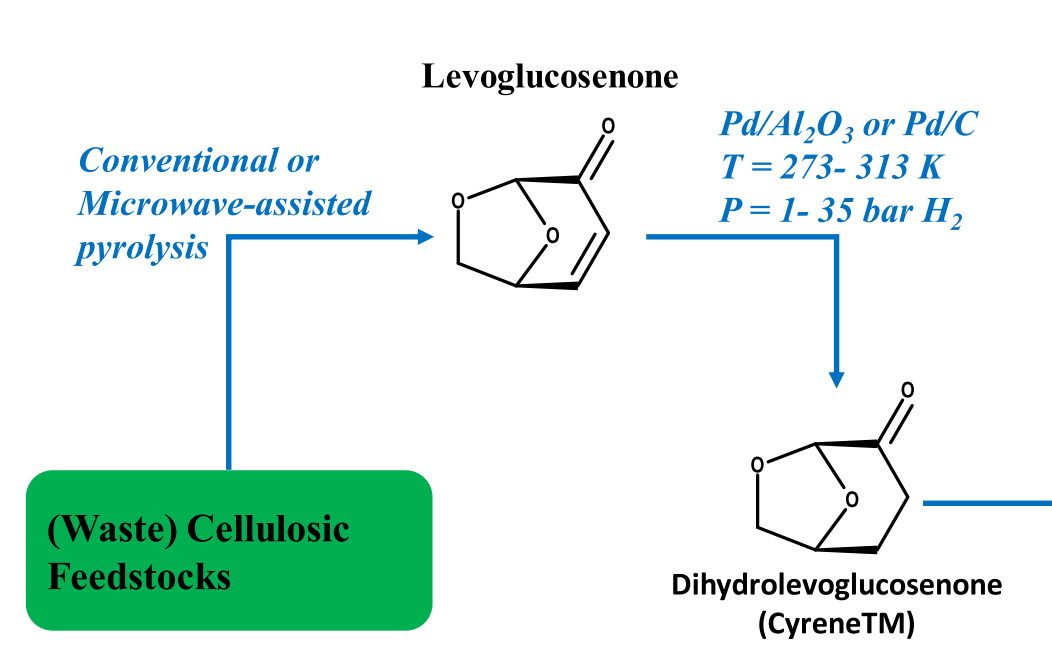

\section{Endo/exo levoglucosanol}

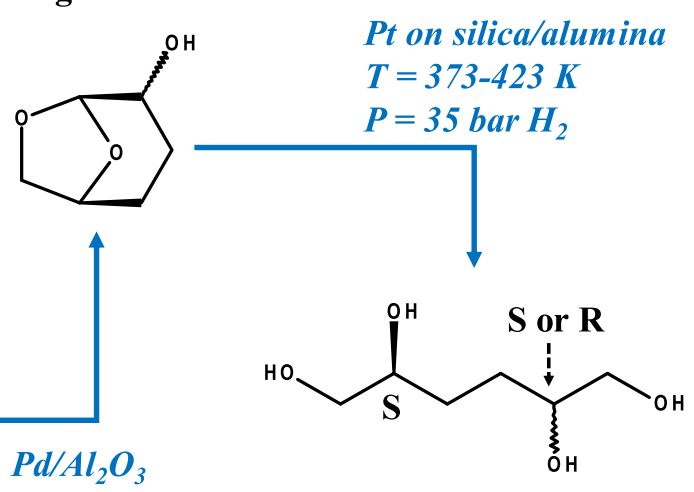

$$
\begin{aligned}
& T=373 \mathrm{~K} \\
& P=35 \text { bar } H_{2}
\end{aligned}
$$

$(\mathrm{S}, \mathrm{S}) /(\mathrm{S}, \mathrm{R})$-hexane-1,2,5,6-tetrol

Figure 1. Overview figure synthesis of $(S, S) /(S, R)$-hexane-1,2,5,6-tetrol from (waste) cellulosic feedstocks.

$(\mathrm{BET})$, yet no data on pore volume and pore size has been published. ${ }^{10,11}$ Notably, the functionalization of these materials with $\mathrm{Au}$ or Pd nanoparticles allowed for (chemoselective) catalytic reduction reactions. ${ }^{10,11}$ Mixing diboronic acid with a chiral indacene-type bis(1,2-diol) gave trimeric microporous cages with surface areas (SAs) of 491 and $582 \mathrm{~m}^{2} \mathrm{~g}^{-1} \cdot{ }^{12}$ Hierarchical structures using dative $\mathrm{B}-\mathrm{N}$ bonds have also been reported. ${ }^{9,13}$ A relative recent addition are the covalent $2 \mathrm{D} / 3 \mathrm{D}$ organic frameworks (COFs). These are micro/mesoporous materials where rigid building blocks, often with a specific geometry and/or symmetry, are interconnected through covalent bonds forming $2 \mathrm{D} / 3 \mathrm{D}$ rigid crystalline porous structures. ${ }^{14}$ Most typically, the boron-based COFs employ catechol building blocks. To date no COF has been reported with a pore diameter larger than $5 \mathrm{~nm}$. In addition, only a few chiral COFs are known, typically using chiral pyrrolidine and tartaric acid derivatives as the linking or pendant groups. ${ }^{15}$ Presently, no chiral boron-based COFs have been reported.

Very recently a novel COF class was introduced where helical polymers are interwoven at regular intervals by means of copper complexes. ${ }^{16}$ Demetalation of this structure (named COF-505) was shown to retain its morphology, at the expense of a certain decrease in crystallinity. ${ }^{16}$ Most importantly, owing to the large flexibility of the $1 \mathrm{D}$ threads in demetalated COF505 , a 10 -fold increase of its elasticity was observed. ${ }^{17}$ Besides weaving, entanglement in porous frameworks can also be achieved by the interpenetration of $2 \mathrm{D} / 3 \mathrm{D}$ frameworks or interlocking of rings. ${ }^{17}$

In spite of the high surface areas and pore volumes, and the related plethora of potential and promising applications, the commercial use of mesoporous materials is still quite a challenge due to their chemical instability, expensive synthesis approaches, and nonstraightforward processability. ${ }^{18}$ The cost of the extended linkers, which is especially relevant for COFs and MOFs, is another major concern with, for instance, only two commercialized MOFs employing linkers with more than one phenyl ring. ${ }^{19}$

Recently, we have reported on the sustainable synthesis of hexane-1,2,5,6-tetrol (HT) in which two 1,2-diol moieties are joined by a flexible ethane bridge. ${ }^{20} \mathrm{HT}$ is derived from cellulose in 3-4 steps many of which involve heterogeneous catalysts. In successive order these comprise (Figure 1) the following list:
(1) Conventional/microwave pyrolysis of (waste) cellulosic polysaccharides. $^{21-23}$

(2) Hydrogenation of levoglucosenone to levoglucosanol over dihydrolevoglucosenone with heterogeneous Pd catalysts (one or two steps). ${ }^{24,25}$ It is noteworthy that presently a joint venture between the Australian Circa Company and the Norwegian multinational Norskeskog is running a fully operational 50 tonnes/year prototype plant in Tasmania. ${ }^{26}$

(3) Combined one pot hydrogenation/hydrolysis of levoglucosanol (one step). ${ }^{20}$

HT is typically obtained as a mixture of two diastereomers notably $(S, R)$-HT (mesomer) and $(S, S)$-HT. Boronic acids are abundantly available due to their importance in SuzukiMiyaura coupling reactions. ${ }^{27,28}$ They are generally considered nontoxic and are easy to synthesize. ${ }^{27,29}$

Here we report on the synthesis of a novel porous organic polymer obtained by reactive dissolution of sparingly soluble HT with simple benzenediboronic acids (BDB) and concomitant precipitation of the mesoporous HT polyboronate. The reaction is conducted at $\mathrm{RT}$ and requires no special reaction conditions such as vacuum, inert atmosphere, or controlled water removal. It is shown that the properties of the resulting mesoporous polymers are largely determined by the chirality of HT and the meta/para orientation of the boronic acids on the phenyl ring. Thereby HT's chirality is likely inducing coiling of the polymer chain, allowing for interweaving of the polymeric chains. These materials are crystalline and in spite of their lower surface areas $\left(30-90 \mathrm{~m}^{2}\right.$ $\mathrm{g}^{-1}$ ) display mesopore volumes up to $0.441 \mathrm{~mL} \mathrm{~g}^{-1}$. Scheme $1 \mathrm{~A}$ provides a visual of the potential polymeric chains indicative of their stereocenters and points of potential molecular rotation. Hereafter these materials are denoted as "HT/polyboronates" or more specifically using the HT/1, $x$ $\mathrm{BDB} /$ solvent formalism.

\section{RESULTS AND DISCUSSION}

Table 1 lists the obtained specific surface areas (SAs) and pore volumes (PVs) as a function of the type of diboronic acid used, the applied solvent, and HT's diastereomeric excess. It is found that the meta orientation of the diboronic acids on the phenyl ring (1,3-BDB) gives higher SA and PV values compared to the para orientation of the diboronic acids (1,4-BDB) (Table 1 , 
Scheme 1. (A) Schematic Visualization of Two Different HT (hexane-1,2,5,6-tetrol)-BDB (1,4- or 1,3-Benzenediboronic Acid) Polymeric Chains with Indication of the Stereocenters and Points of Potential Rotation of the Molecular Chains, (B) Illustrative Variability of the Growing Polymeric Chain When Incorporating Chirally Pure $(R, S)$-HT [Shown as (R-S)], and (C) Unique Chiral Polymer When Constructing the Polymeric Chain from $(S, S)$-HT $[$ Shown as $(S-S)]$

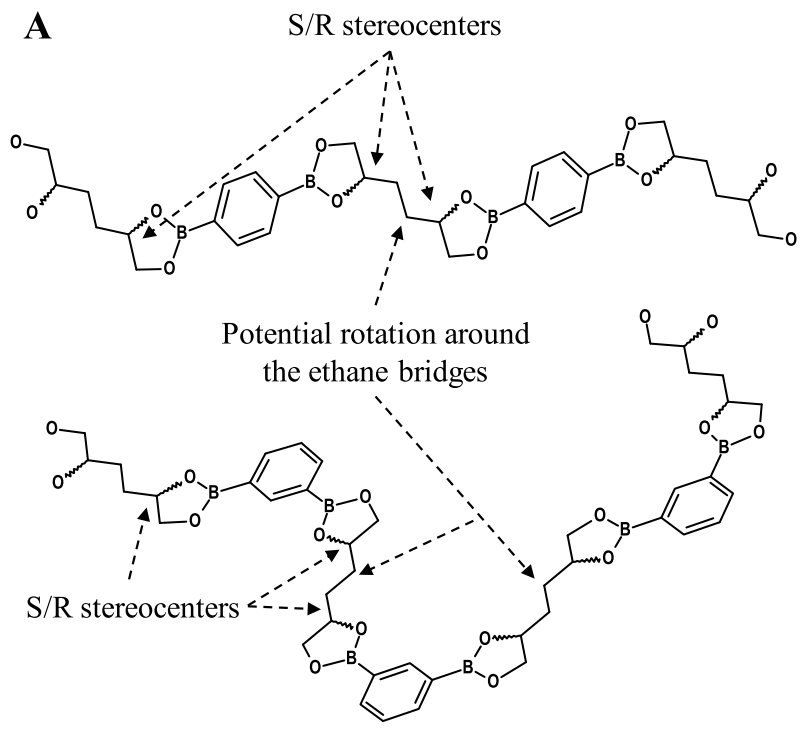

B: HT/polyboronate polymers using chiral (R,S)-HT:

$\rightarrow(\mathrm{R}-\mathrm{S})-\mathrm{BDB}-(\mathrm{R}-\mathrm{S})-$

$\rightarrow$ (R-S)-BDB-(R-S)-BDB-(R-S)-

$\rightarrow$ (R-S)-BDB-(R-S)-BDB-(S-R)-

(R-S)-BDB Extensive variability as the chiral polymeric chain grows

$$
\begin{aligned}
\longrightarrow & (\mathrm{R}-\mathrm{S})-B D B-(\mathrm{S}-\mathrm{R})-B D B-(\mathrm{S}-\mathrm{R})- \\
& \\
& (\mathrm{R}-\mathrm{S})-\mathrm{BDB}-\mathrm{S}-\mathrm{S}-\mathrm{R})-\mathrm{BDB}-(\mathrm{S}-\mathrm{R})-\mathrm{BDB}-(\mathrm{R}-\mathrm{S})-
\end{aligned}
$$

\section{C: HT/polvboronate polvmers using chiral (S,S)-HT:}

$(\mathrm{S}-\mathrm{S})-\mathrm{BDB} \otimes \quad(\mathrm{S}, \mathrm{S})-\mathrm{BDB}-(\mathrm{S}, \mathrm{S})-\mathrm{BDB}-(\mathrm{S}, \mathrm{S})-\mathrm{BDB}-(\mathrm{S}, \mathrm{S})-\mathrm{BDB}-(\mathrm{S}, \mathrm{S})-\mathrm{BDB}$ etc.

Unique chiral polymeric chain

entries $a / b)$. This suggests for a distinct influence of the curvature of the polymeric chain. Interestingly, the use of $4,4^{\prime}$ biphenyldiboronic acid (4,4'-BPDB) led to quasi similar results as obtained with 1,3-BDB (Table 1 , entry c). This can be rationalized by the nonplanarity of biphenyl units and the consequent absence of $\mathrm{p}-\mathrm{p}$ stacking of the aromatic rings. The use of acetone or $\mathrm{CH}_{2} \mathrm{Cl}_{2}$ as the reaction solvents gives higher SAs and PVs than when THF or AcCN are used (Table 1 entries $\mathrm{d}-\mathrm{g}$ ). Additionally, the SA and PV values benefit also from higher reaction volumes (Table 1 , entries $\mathrm{d}, \mathrm{h}$, and $\mathrm{i}$ ).

Partial enrichment of $(S, R)$-HT over $(S, S)$-HT was described in a previous publication. ${ }^{20}$ Specific crystallization of the $(S, R)$-HT diastereomer was achieved from hot 1,4dioxane, allowing for the evaluation of HT's chirality on the properties of the $\mathrm{HT} /$ polyboronates. Unfortunately, it has presently not been found possible to crystallize/purify $(S, S)$ HT. It is noteworthy that $(S, R)$-HT is a mesomer, making that it displays no net chirality on its own but does so effectively in
Table 1. Survey of the Specific Surface Areas and Specific Pore Volumes for a Range of HT (Hexane-1,2,5,6-tetrol)

\begin{tabular}{|c|c|c|c|c|c|}
\hline entry & component 1 & component 2 & solvent & $\begin{array}{c}\text { spec surface } \\
\text { area } \\
\left(\mathrm{m}^{2} \mathrm{~g}^{-1}\right) \\
\mathrm{BET}\end{array}$ & $\begin{array}{l}\text { spec pore } \\
\text { volume } \\
\left(\mathrm{mL} \mathrm{g}^{-1}\right)\end{array}$ \\
\hline $\mathrm{a}$ & $\begin{array}{c}\text { HT } 38 \% \\
1<2\end{array}$ & 1,4-BDB & THF & 42 & 0.227 \\
\hline $\mathrm{b}$ & $\begin{array}{c}\text { HT } 38 \% \\
1<2\end{array}$ & 1,3-BDB & THF & 65.8 & 0.408 \\
\hline c & $\begin{array}{c}\text { HT } 38 \% \\
1<2\end{array}$ & 4,4'-BPDB & THF & 64.5 & 0.359 \\
\hline d & $\begin{array}{c}\text { HT } 38 \% \\
1>2\end{array}$ & 1,3-BDB & THF & 60.5 & 0.315 \\
\hline $\mathrm{e}$ & $\begin{array}{c}\text { HT } 38 \% \\
1>2\end{array}$ & 1,3-BDB & $\mathrm{CH}_{2} \mathrm{Cl}_{2}$ & 74.0 & 0.397 \\
\hline f & $\begin{array}{c}\mathrm{HT} 38 \% \\
1>2\end{array}$ & 1,3-BDB & $\mathrm{AcCN}$ & 61.2 & 0.290 \\
\hline $\mathrm{g}$ & $\begin{array}{c}\text { HT } 38 \% \\
1>2\end{array}$ & 1,3-BDB & acetone & 67.2 & 0.440 \\
\hline $\mathrm{h}$ & $\begin{array}{c}\text { HT } 38 \% \\
1>2\end{array}$ & 1,3-BDB & $\begin{array}{l}\text { THF } \\
5 \mathrm{~mL}\end{array}$ & 49.1 & 0.289 \\
\hline $\mathrm{i}$ & $\begin{array}{c}\text { HT } 38 \% \\
1>2\end{array}$ & 1,3-BDB & $\begin{array}{l}\text { THF } \\
45 \mathrm{~mL}\end{array}$ & 62.8 & 0.407 \\
\hline $\mathrm{j}$ & $\begin{array}{c}\text { HT } 38 \% \\
1<2\end{array}$ & $1,3-\mathrm{BDB}$ & acetone & 51.3 & 0.271 \\
\hline $\mathrm{k}$ & $\begin{array}{c}\text { HT } 98 \% \\
1>2\end{array}$ & $1,3-\mathrm{BDB}$ & THF & 80.7 & 0.412 \\
\hline 1 & $\begin{array}{c}\text { HT } 98 \% \\
1>2\end{array}$ & 1,4-BDB & THF & 32.8 & 0.148 \\
\hline $\mathrm{m}$ & $\begin{array}{c}\text { HT } 98 \% \\
1>2\end{array}$ & $1,3-\mathrm{BDB}$ & acetone & 87.3 & 0.441 \\
\hline
\end{tabular}
Containing Polyboronate Esters

${ }^{a}$ Unless otherwise stated, the used solvent volume is $15 \mathrm{~mL} ; 1=$ $(S, R)-\mathrm{HT}$ and $2=(S, S)-\mathrm{HT}$; the $38 \%$ and $98 \%$ refer to diastereomeric excesses (d.e.).

a polymeric setting. Given that $(S, R)$-HT can build into the polymeric chain as $(S, R)$ or $(R, S)$, substantial variability in the curvature of the polymeric chain is likely present (Scheme $1 \mathrm{~B}$ / $C)$. Actual and distinct influences of the diastereomeric $(S, R) /$ $(S, S)$ ratio in HT on the properties of the materials are observable:

(A) In using $38 \%$ d.e. $(S, R)$-HT, higher SA and PV are obtained then when $38 \%$ d.e. $(S, S)$-HT is used (Table 1 , entries $g$ vs $j$ ).

(B) Elevating the d.e. in $(S, R)$-HT from 38 to $98 \%$ is found to increase both the SA and PV by around 30\% for HT/ 1,3-BDB/THF (Table 1 , entries $\mathrm{k} \leftrightarrow \mathrm{d}$ ). In the case of $\mathrm{HT} / 1,3-\mathrm{BDB} /$ acetone, only an SA increase of $30 \%$ is observed with an already high PV (Table 1 , entries $\mathrm{m}$ vs g).

(C) Using diastereomerically pure $(S, R)$-HT magnifies the effect of the meta/para orientation of BDB on the spread in SA and PV (Table 1, entries a, b, k, and 1).

It is noteworthy that no cooperative stereochemical effect occurs as hydrolysis of the formed $\mathrm{HT}$ /polyboronates does not reveal a preferential incorporation of one of the HT diastereomers. Irrespective the nature of the $\mathrm{HT} /$ polyboronates, the obtained SA and PV values correlate to a certain degree (Figure S1_A).

In terms of yield, reactions between HT with $38 \%$ d.e. $(1>2$ or $1<2$ ) and 1,4-BDB typically give between 65 and $75 \%$ yield of the solid HT/1,4-BDB polyboronate product. This is 73$85 \%$ of the theoretical yield which is $88.6 \%$ given the loss of two waters molecules during the condensation of HT and 

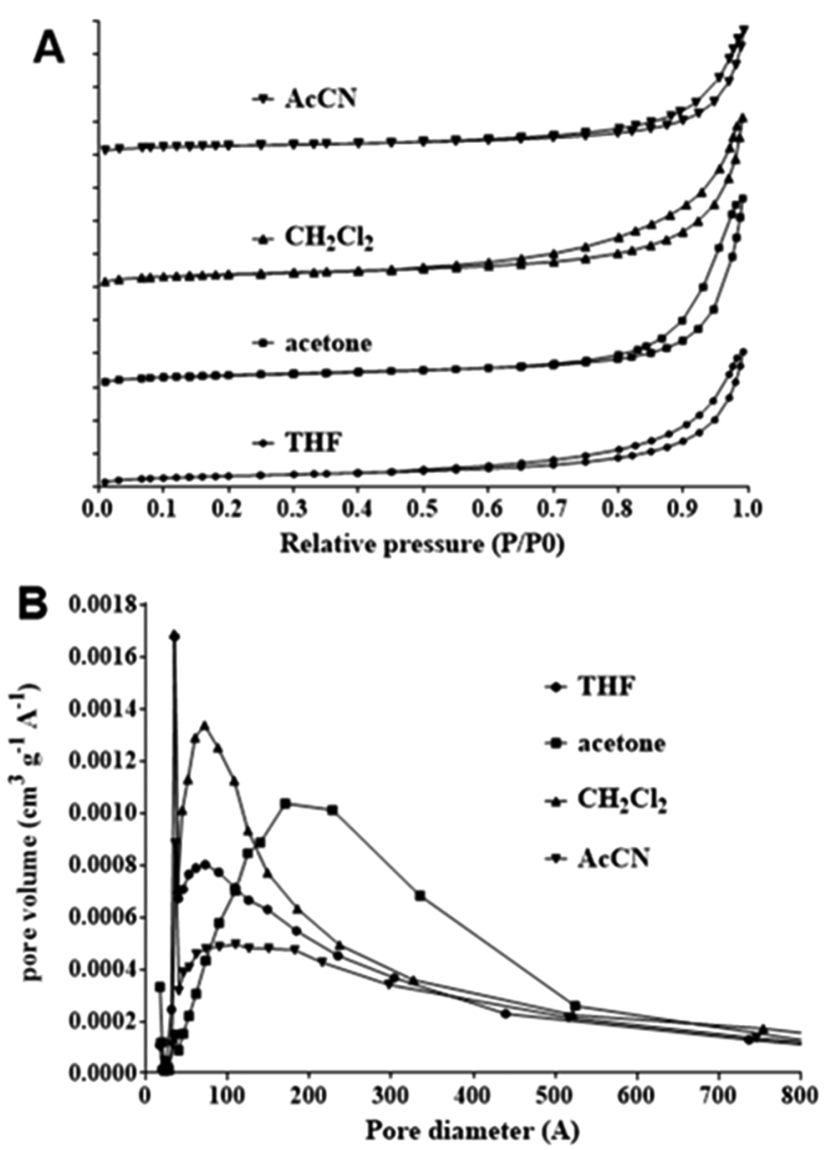

Figure 2. $\mathrm{N}_{2}$ adsorption isotherms (A) and pore size distributions (B) for HT (hexane-1,2,5,6-tetrol)-1,3-BDB (1,3-benzenediboronic acid) made with four different solvents.

BDB. Reactions between HT with $38 \%$ d.e. $(1>2$ or $1<2)$ and 1,3-BDB typically give between 55 and $65 \%$ yield of the solid HT/1,3-BDB polyboronate product. This is $62-73 \%$ of the theoretical yield. Reactions using pure HT (i.e., > 98\% d.e.) are with 26-30\% much lower yielding, and this irrespective of the HT diastereomer and the BDB nature.

As shown in Figure $2 \mathrm{~A}$, the $\mathrm{N}_{2}$ physisorption isotherms display a type IV isotherm and an $\mathrm{H} 3$ hysteresis. The latter is indicative of aggregates of platelike particles forming slitlike pores. ${ }^{30}$ This is reminiscent of the pentaerythrithol/1,4-BDB (PE/1,4-BDB) material reported by Fujiwara et al. and Matsushima et al. ${ }^{10,11}$ with the difference that the $\mathrm{N}_{2}$ adsorption is fully reversible, strengthening our claim on mesoporous materials. Larger variably sized mesopores, spanning mainly the 5-50 $\mathrm{nm} \varnothing$ range, are evidenced (Figure 2B). The sharp peak at $3.7 \mathrm{~nm}$ is an artifact relating to forced closure of the sorption hysteresis. ${ }^{31}$ As can be inferred from Figure $2 \mathrm{~B}$, the pore size distribution is solvent dependent with the use of acetone leading to a larger mean pore diameter than when THF is used.

The here reported maximal PV of $0.44 \mathrm{~mL} \mathrm{~g}^{-1}$ is comparable to the one reported for the [MeOAc] $50-\mathrm{H} 2 \mathrm{P}\left(0.42 \mathrm{~mL} \mathrm{~g}^{-1}\right)$ $\mathrm{COF}$ yet obtained in a less expensive and more benign fashion than the COF. ${ }^{32}$ The marked difference in SA between the $\mathrm{HT} /$ polyboronates and the latter COF material (90 vs $754 \mathrm{~m}^{2}$ $\left.\mathrm{g}^{-1}\right)$ relates to the much larger pore diameters of the materials reported here $(\varnothing 5-50 \mathrm{~nm})$ vis-à-vis the one for the above stated COF $(\varnothing 1.8 \mathrm{~nm})$.
SEM analysis of $98 \%$ d.e. $(R, S)$-HT/1,4-BDB/THF (Figure $3 \mathrm{~A}$ series), $98 \%$ d.e. $(R, S)-\mathrm{HT} / 1,3-\mathrm{BDB} / \mathrm{THF}$ (Figure 3B series), and $98 \%$ d.e. $(R, S)-\mathrm{HT} / 1,3-\mathrm{BDB} /$ acetone (Figure $3 \mathrm{C}$ series) reveals the following:

- Micrometer-sized particles (Figure 3A1/B1/C1).

- Aggregates of plates for $98 \%$ d.e. $(R, S)-\mathrm{HT} / 1,4-\mathrm{BDB} /$ THF (Figure 3A2/A3).

- A more pronounced pore structure when 1,3-BDB is used over 1,4-BDB (Figure 3B1/B2). Here the plate aggregates form channels and cell-like structures. Interestingly, some of the observed plate-like structures seem to have delaminated which may have contributed positively to the observed enhanced porosity (Figure 3B3).

- Using acetone as the reaction solvent yields equally a highly porous structure yet with a substantially different fine-structure (on the micrometer level) than observed when THF is used (Figure 3B2/B3 vs Figure 3C2/C3).

Overall the dimensions of the irregular voids between the platelets, as channels or cell-like structures, are in the tens of nanometers and thus consistent with the $\mathrm{N}_{2}$ physisorption results and the appearance of an $\mathrm{H} 3$ hysteresis in the $\mathrm{N}_{2}$ physisorption experiments. In spite of the high melting temperatures of the $\mathrm{HT} /$ polyboronates $(\sim 600 \mathrm{~K})$, TEM imaging was found impossible due to melting of the materials under the electron beam. XRD revealed a degree of crystallinity in all $\mathrm{HT}$ /polyboronates with the nature of the BDB (length, substitution pattern) affecting markedly the appearance of the different XRD patterns (Figure 4). Given the characteristic $\mathrm{H} 3$ hysteresis loop in the $\mathrm{N}_{2}$ physisorption experiments and the absence of order in the SEM images (Figure 3), we assume that the observed crystallinity reflects some ordering in the pore wall structure. The nature of the used solvent has no effect on the crystallinity (Figure S2). The diastereoselectivity of HT affects the crystallinity only in the case of the 1,4-BDB linker (Figure 5).

The $(S, R)$-HT/1,4-BDB and $(S, R)$-HT/1,3-BDB polyboronates were characterized by ${ }^{13} \mathrm{C} C \mathrm{CP}$-MAS and ${ }^{11} \mathrm{~B}$ spin echo MAS NMR, and the results are shown in Figure 6. Analytical simulations of the ${ }^{11} \mathrm{~B}$ spectra confirmed the existence of only one type of boron species, and this is irrespective of the nature of the BDB unit. (Figure 6B/D, red curve). FT-IR spectroscopy further confirmed the presence of boronate esters with characteristic vibrational peaks in the $1320-1300 \mathrm{~cm}^{-1}(\mathrm{~B}-\mathrm{O}$ stretch) and $690-650 \mathrm{~cm}^{-1}$ (characteristic boronate ester peak $^{33}$ ) spectral ranges (Figure S3_A). ${ }^{11,34}$ In addition, FT-IR spectroscopy revealed the clear absence of $\mathrm{OH}$ groups (3500$\left.3000 \mathrm{~cm}^{-1}\right)$, characteristic for the residual presence of HT or incomplete boronate ester formation in the synthesized HT/ polyboronates (Figures S3_B/C).

\section{CONCLUSIONS}

A range of new crystalline (chiral) mesoporous materials were obtained by the facile and benign condensation of (chiral), biobased hexane-1,2,5,6-tetrol (HT) and simple aromatic diboronic acids. The so formed mesoporous HT/polyboronates are obtained by spontaneous precipitation from the reaction mixture, not requiring an extensive workup procedure. $\mathrm{HT}$ is easily accessible from cellulose and chiral pure $(R, S)$-HT is straightforward to crystallize. The applied simple diboronic acids are abundantly available due to their commercial use in Miyaura-Suzuki reactions, easy to synthesize, and generally 

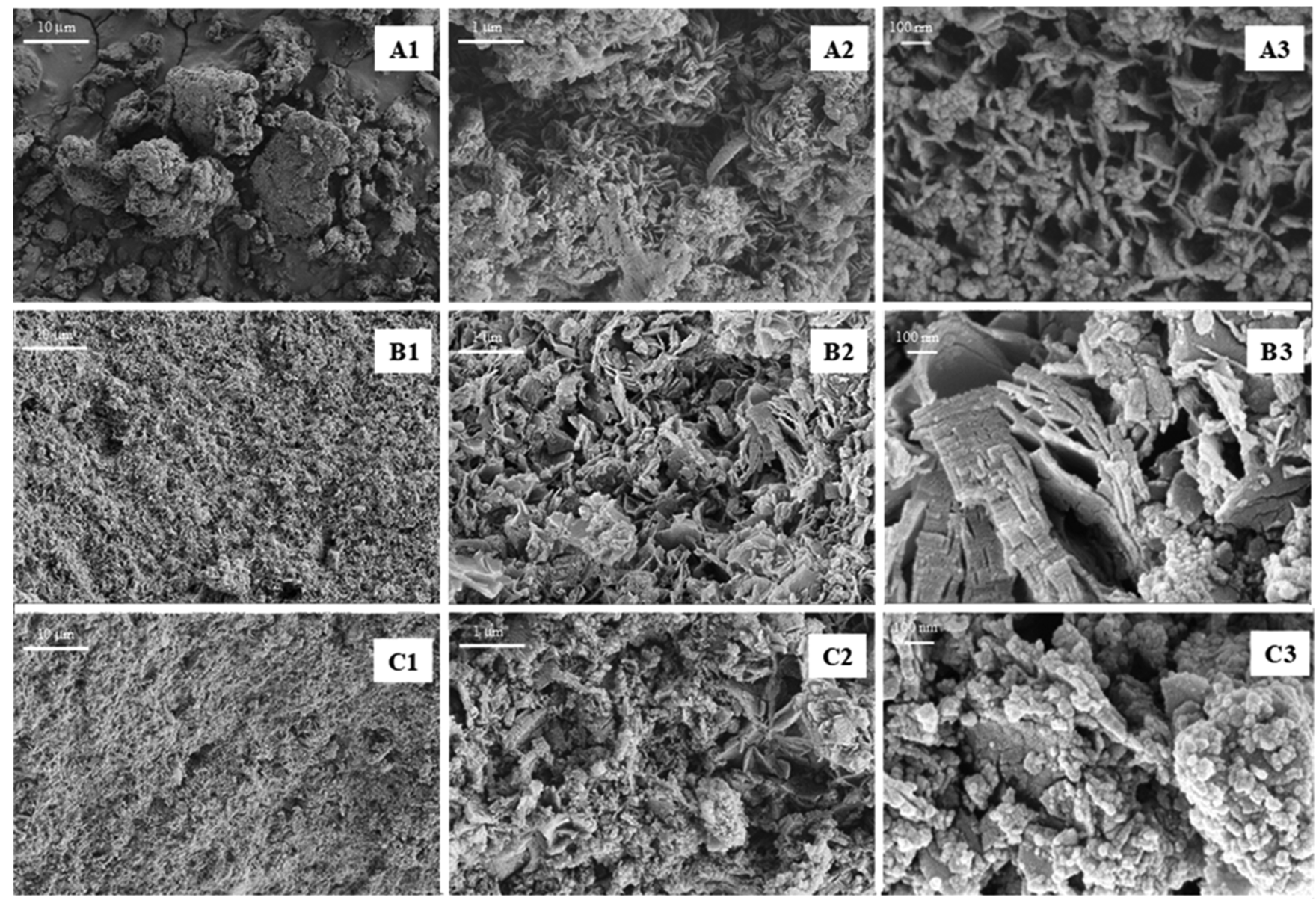

Figure 3. Scanning electron microscopy (SEM) images of $98 \%$ d.e. ( $R, S)$-HT/1,4-BDB/THF (parts A1, A2, A3), 98\% d.e. (R,S)-HT/1,3-BDB/ THF (parts B1, B2, B3), and $98 \%$ d.e. $(R, S)-\mathrm{HT} / 1,3-\mathrm{BDB} /$ acetone (parts C1 C2 C3).

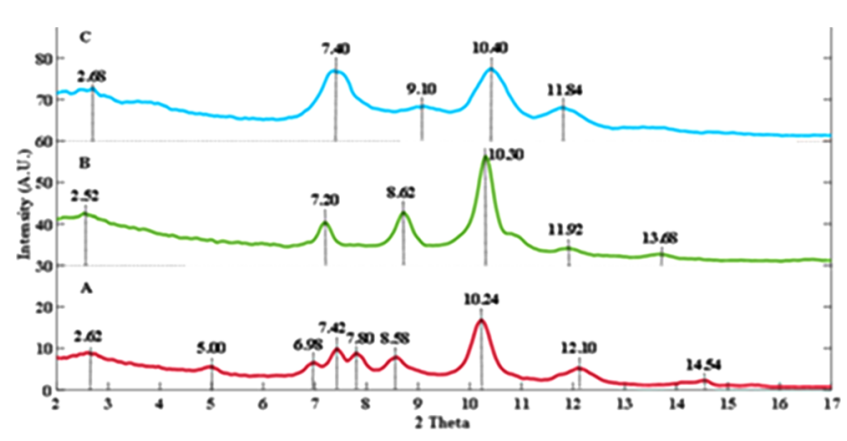

Figure 4. X-ray diffractograms (XRD) of (A) HT/1,4-BDB, (B) HT/ 1,3-BDB, and (C) HT/4,4'-BPDB; no background subtraction.

considered nontoxic. $^{35-37}$ The low cost of these materials is ultimately considered to benefit potential commercial applications. The reported materials show an appreciable pore volume of up to $0.44 \mathrm{~mL} \mathrm{~g}^{-1}$, rivalling the pore volumes of some reported COF materials yet obtained in a less expensive way. Importantly, presently no COF has been reported with pore diameters in excess of $5 \mathrm{~nm}$. The $(R, S)$-HT ( $98 \%$ d.e.)/polyboronate represents a first example of a chiral mesoporous polyboronate. The high pore volume and the larger pore sizes of 5-50 $\mathrm{nm}$ offer great potential to the incorporation of enzymes or as supports to immobilize catalysts to convert bulkier substrates. The meta/para orientation of the boronic acids on the phenyl ring was shown to influence the obtainable surface areas and pore

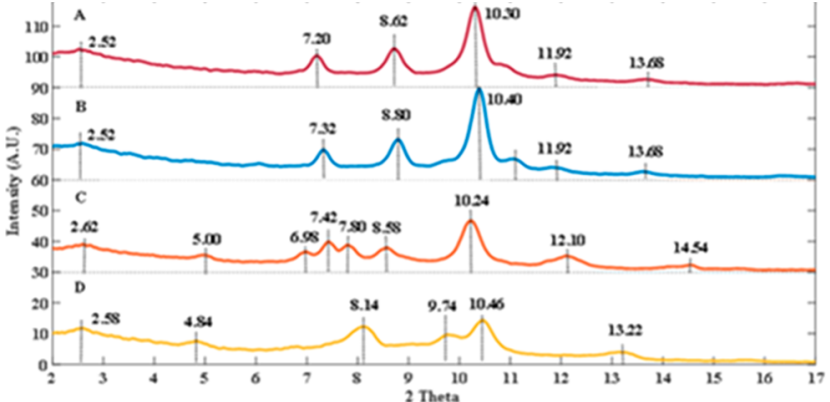

Figure 5. X-ray diffractograms (XRD) of HT/1,3-BDB (A 38\% HT d.e.; B 98\% HT d.e.) and HT/1,4-BDB (C 38\% HT d.e.; D 98\% HT d.e.); $\mathrm{PHT}=$ chirally pure $\mathrm{HT}$.

volumes. Uniquely, a distinct influence of HT's chirality (its d.e. value) on the materials' properties was evidenced. Future work will focus on testing these new materials toward a wide range of different applications, thereby hopefully demonstrating its potential as a valuable material.

\section{ASSOCIATED CONTENT}

\section{S Supporting Information}

The Supporting Information is available free of charge on the ACS Publications website at DOI: 10.1021/acssuschemeng.9b02772. 


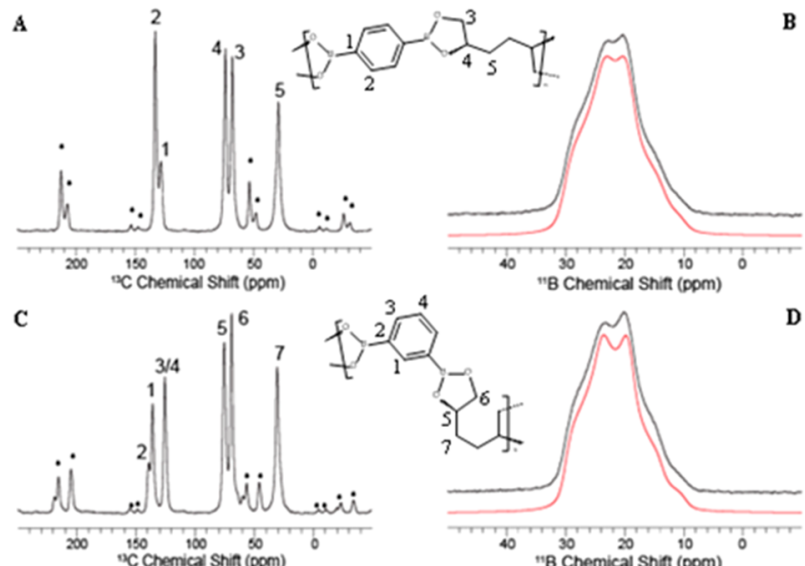

Figure 6. ${ }^{13} \mathrm{C}$ CP-MAS NMR of (A) (S,R)-HT/1,4-BDB and (C) $(S, R)-\mathrm{HT} / 1,3-\mathrm{BDB} ;{ }^{11} \mathrm{~B}$ spin echo MAS NMR of $(\mathrm{B})(S, R)-\mathrm{HT} / 1,4-$ $\mathrm{BDB}$ and $(\mathrm{D})(S, R)-\mathrm{HT} / 1,3-\mathrm{BDB} ; *$ = spinning sideband.

Experimental procedures, additional X-ray diffractograms, and FT-IR spectra (PDF)

\section{AUTHOR INFORMATION}

\section{Corresponding Author}

*Email: mario.debruyn@gmail.com.

\section{ORCID}

Mario De bruyn: 0000-0002-9687-1606

Ive Hermans: 0000-0001-6228-9928

James A. Dumesic: 0000-0001-6542-0856

Bert M. Weckhuysen: 0000-0001-5245-1426

\section{Funding}

European Union's Horizon 2020 research and innovation program under grant agreement No. 701028 (EU Marie Curie Global Fellowship).

\section{Notes}

The authors declare no competing financial interest.

\section{ACKNOWLEDGMENTS}

M.D.b. acknowledges the European Union's Horizon 2020 research and innovation programme under grant agreement No. 701028 (EU Marie Curie Global Fellowship). Tony Duncan (Circa) is thanked for the generous provision of Cyrene from which HT is prepared. The authors gratefully acknowledge the use of facilities and instrumentation supported by NSF through the University of Wisconsin Materials Research Science and Engineering Center (DMR1720415). Special thanks go to Richard Noll (University of Wisconsin) for his assistance with SEM imaging.

\section{REFERENCES}

(1) Linares, N.; Silvestre-Albero, A. M.; Serrano, E.; Silvestre-Albero, J.; Garcia-Martinez, J. Mesoporous materials for clean energy technologies. Chem. Soc. Rev. 2014, 43, 7681-7717.

(2) Libbrecht, W.; Verberckmoes, A.; Thybaut, J. W.; Van der Voort, P.; De Clercq, J. Soft templated mesoporous carbons: Tuning the porosity for the adsorption of large organic pollutants. Carbon 2017, $116,528-546$.

(3) Gu, D.; Schuth, F. Synthesis of non-siliceous mesoporous oxides. Chem. Soc. Rev. 2014, 43, 313-344.

(4) Suib, S. L. A Review of Recent Developments of Mesoporous Materials. Chem. Rec 2017, 17, 1169-1183.
(5) Liu, D. X.; Zou, D. T.; Zhu, H. L.; Zhang, J. Y. Mesoporous Metal-Organic Frameworks: Synthetic Strategies and Emerging Applications. Small 2018, 14, 1801454.

(6) Xin, W.; Song, Y. H. Mesoporous carbons: recent advances in synthesis and typical applications. RSC Adv. 2015, 5, 83239-83285.

(7) Croissant, J. G.; Cattoen, X.; Man, M. W. C.; Durand, J. O.; Khashab, N. M. Syntheses and applications of periodic mesoporous organosilica nanoparticles. Nanoscale 2015, 7, 20318-20334.

(8) White, R. J.; Shuttleworth, P. S.; Budarin, V. L.; De Bruyn, M.; Fischer, A.; Clark, J. H. An Interesting Class of Porous PolymerRevisiting the Structure of Mesoporous alpha-D-Polysaccharide Gels. ChemSusChem 2016, 9, 280-288.

(9) Kubo, Y.; Nishiyabu, R.; James, T. D. Hierarchical supramolecules and organization using boronic acid building blocks. Chem. Commun. 2015, 51, 2005-2020.

(10) Fujiwara, S.; Takanashi, N.; Nishiyabu, R.; Kubo, Y. Boronate microparticle-supported nano-palladium and nano-gold catalysts for chemoselective hydrogenation of cinnamaldehyde in environmentally preferable solvents. Green Chem. 2014, 16, 3230-3236.

(11) Matsushima, Y.; Nishiyabu, R.; Takanashi, N.; Haruta, M.; Kimura, H.; Kubo, Y. Boronate self-assemblies with embedded Au nanoparticles: preparation, characterization and their catalytic activities for the reduction of nitroaromatic compounds. J. Mater. Chem. 2012, 22, 24124-24131.

(12) Ono, K.; Aizawa, R.; Yamano, T.; Ito, S.; Yasuda, N.; Johmoto, K.; Uekusa, H.; Iwasawa, N. Procedure-dependent construction of two isomers of trimeric self-assembled boronic esters. Chem. Commun. 2014, 50, 13683-13686.

(13) Dhara, A.; Beuerle, F. Reversible Assembly of a Supramolecular Cage Linked by Boron-Nitrogen Dative Bonds. Chem. - Eur. J. 2015, 21, 17391-17396.

(14) Lohse, M. S.; Bein, T. Covalent Organic Frameworks: Structures, Synthesis, and Applications. Adv. Funct. Mater. 2018, 28, 1705553.

(15) Han, X.; Zhang, J.; Huang, J. J.; Wu, X. W.; Yuan, D. Q.; Liu, Y.; Cui, Y. Chiral induction in covalent organic frameworks. Nat. Commun. 2018, 9, 1294.

(16) Liu, Y. Z.; Ma, Y. H.; Zhao, Y. B.; Sun, X. X.; Gandara, F.; Furukawa, H.; Liu, Z.; Zhu, H. Y.; Zhu, C. H.; Suenaga, K.; Oleynikov, P.; Alshammari, A. S.; Zhang, X.; Terasaki, O.; Yaghi, O. $\mathrm{M}$. Weaving of organic threads into a crystalline covalent organic framework. Science 2016, 351, 365-369.

(17) Diercks, C. S.; Yaghi, O. M. The atom, the molecule, and the covalent organic framework. Science 2017, 355, eaal1585.

(18) Kandambeth, S.; Dey, K.; Banerjee, R. Covalent organic frameworks: chemistry beyond the structure. J. Am. Chem. Soc. 2019, $141,1807-1822$.

(19) Peh, S. B.; Wang, Y.; Zhao, D. Scalable and sustainable synthesis of advanced porous materials. ACS Sustainable Chem. Eng. 2019, 7, 3647-3670.

(20) Krishna, S. H.; De bruyn, M.; Schmidt, Z. R.; Weckhuysen, B. M.; Dumesic, J. A.; Huber, G. W. Catalytic production of hexane1,2,5,6-tetrol from bio-renewable levoglucosanol in water: effect of metal and acid sites on (stereo)-selectivity. Green Chem. 2018, 20, 4557-4565.

(21) Court, G. R.; Lawrence, C. H.; Raverty, W. D.; Duncan, A. J. Method for converting lignocellulosic materials into useful chemicals. WO Patent 2011/000030 A1, 2011.

(22) De Bruyn, M.; Fan, J.; Budarin, V. L.; Macquarrie, D. J.; Gomez, L. D.; Simister, R.; Farmer, T. J.; Raverty, W. D.; McQueenMason, S. J.; Clark, J. H. A new perspective in bio-refining: levoglucosenone and cleaner lignin from waste biorefinery hydrolysis lignin by selective conversion of residual saccharides. Energy Environ. Sci. 2016, 9, 2571-2574.

(23) Bouxin, F. P.; Clark, J. H.; Fan, J. J.; Budarin, V. Combining steam distillation with microwave-assisted pyrolysis to maximise direct production of levoglucosenone from agricultural wastes. Green Chem. 2019, 21, 1282-1291. 
(24) Krishna, S. H.; McClelland, D. J.; Rashke, Q. A.; Dumesic, J. A.; Huber, G. W. Hydrogenation of levoglucosenone to renewable chemicals. Green Chem. 2017, 19, 1278-1285.

(25) Sherwood, J.; De Bruyn, M.; Constantinou, A.; Moity, L.; McElroy, C. R.; Farmer, T. J.; Duncan, T.; Raverty, W.; Hunt, A. J.;

Clark, J. H. Dihydrolevoglucosenone (Cyrene) as a bio-based alternative for dipolar aprotic solvents. Chem. Commun. 2014, 50, 9650-9652.

(26) Krishna, S. H.; Huang, K. F.; Barnett, K. J.; He, J. Y.; Maravelias, C. T.; Dumesic, J. A.; Huber, G. W.; De Bruyn, M.; Weckhuysen, B. M. Oxygenated commodity chemicals from chemocatalytic conversion of biomass derived heterocycles. AIChE J. 2018, 64, 1910-1922.

(27) Lennox, A. J. J.; Lloyd-Jones, G. C. Selection of boron reagents for Suzuki-Miyaura coupling. Chem. Soc. Rev. 2014, 43, 412-443.

(28) Polshettiwar, V.; Decottignies, A.; Len, C.; Fihri, A. SuzukiMiyaura Cross-Coupling Reactions in Aqueous Media: Green and Sustainable Syntheses of Biaryls. ChemSusChem 2010, 3, 502-522.

(29) Hooshmand, S. E.; Heidari, B.; Sedghi, R.; Varma, R. S. Recent advances in the Suzuki-Miyaura cross-coupling reaction using efficient catalysts in eco-friendly media. Green Chem. 2019, 21, 381-405.

(30) Sing, K. S. W.; Everett, D. H.; Haul, R. A. W.; Moscou, L.; Pierotti, R. A.; Rouquerol, J.; Siemieniewska, T. Reporting Physisorption Data for Gas Solid Systems with Special Reference to the Determination of Surface-Area and Porosity (Recommendations 1984). Pure Appl. Chem. 1985, 57, 603-619.

(31) Schuth, F.; Ward, M. D.; Buriak, J. M. Common Pitfalls of Catalysis Manuscripts Submitted to Chemistry of Materials. Chem. Mater. 2018, 30, 3599-3600.

(32) Zhu, L. J.; Zhang, Y. B. Crystallization of Covalent Organic Frameworks for Gas Storage Applications. Molecules 2017, 22, 1149.

(33) Tilford, R. W.; Gemmill, W. R.; zur Loye, H. C.; Lavigne, J. J. Facile synthesis of a highly crystalline, covalently linked porous boronate network. Chem. Mater. 2006, 18, 5296-5301.

(34) Smith, M. K.; Northrop, B. H. Vibrational Properties of Boroxine Anhydride and Boronate Ester Materials: Model Systems for the Diagnostic Characterization of Covalent Organic Frameworks. Chem. Mater. 2014, 26, 3781-3795.

(35) Kotha, S.; Lahiri, K.; Kashinath, D. Recent applications of the Suzuki-Miyaura cross-coupling reaction in organic synthesis. Tetrahedron 2002, 58, 9633-9695.

(36) Hussain, I.; Capricho, J.; Yawer, M. A. Synthesis of Biaryls via Ligand-Free Suzuki-Miyaura Cross-Coupling Reactions: A Review of Homogeneous and Heterogeneous Catalytic Developments (vol. 21, pg. 3320, 2016). Adv. Synth. Catal. 2016, 358, 3907-3907.

(37) Martina, K.; Manzoli, M.; Gaudino, E. C.; Cravotto, G. EcoFriendly Physical Activation Methods for Suzuki-Miyaura Reactions. Catalysts 2017, 7, 98. 